\title{
Signaling molecules from Lactuca sativa L. induced quorum sensing phenotypes in bacteria
}

\author{
Esmaeil Mahmoudi*
}

Department of Plant Protection, Islamic Azad University, Isfahan (Khorasgan) Branch, P.O. Box 81595-158 Isfahan, Iran

Received: August 30, 2014

Accepted: April 13, 2015

\begin{abstract}
The outcome of the present investigation revealed that lettuce (Lactuca sativa L.) extract strongly interferes with acyl homoserine lactone (AHL) regulated physiological functions in the bioreporter strain, Chromobacterium violaceum CV026. Extracts of L. sativa also promoted production of virulence factors in plant pathogen, Pectobacterium carotovorum, and significantly increased tissue maceration on potato tubers when there was a low concentration $\left(10^{3} \mathrm{cfu} \cdot \mathrm{ml}^{-1}\right)$ of the bacterium was used. The thin layer chromatogram which visualised with AHL bioreporter strain, CV026, showed that L. sativa extract produced a circular spot with a diffuse edge tail and migrated with the same mobility as standard N-hexanoyl-L-homoserine lactone (C6-HSL). Gas Chromatography Mass Spectroscopy (GC-MS) analysis of the lettuce extract resulted in the identification of 19 compounds of which homoserine was identified for the first time in plants. Homoserine accounted for $2.37 \%$ of the total constituents. It is a new finding that lettuce contains AHL like substances (homoserine) which excite AHL related quorum sensing (QS) in bacteria.
\end{abstract}

Key words: homoserine, lettuce, Pectobacterium carotovorum, quorum sensing

\section{Introduction}

Bacterial quorum sensing (QS) is a density-dependent regulatory system that enables bacteria to make communal decisions. This form of gene expression which relies on the secretion and perception of small signal molecules (called "Quoromons"), by bacterial cells, utilise to ensure that some functions are only expressed when a particular population density has been reached (Mahmoudi et al. 2013a; Lade et al. 2014). The two most widely studied QS signals are the peptide based QS system in Gram-positive bacteria, which operate through membrane bound receptor histidine kinases, and acyl homoserine lactones (AHL) produced by more than 70 species of Gram-negative bacteria, which diffuse across the cell membrane and bind to regulatory proteins within the cell (Waters and Bassler 2005; Amara et al. 2011). In many pathogenic bacteria, the production of virulence determinants are regulated by QS. This allows the bacteria to remain invisible to the host defense systems until the population is sufficiently large enough to successfully establish the infection and overwhelm the host (Essarts et al. 2013).

It could be that the AHL signaling system is a promising target for developing novel approaches to control bacterial infections. Recently, some chemicals were found to act as AHL antagonists and inhibit bacterial QS (Cotar 2013; Mohamed 2014). The known small chemicals with QS inhibition activity were grouped into two categories according to their structures and functions. One group is the structural mimics of QS signals, such as the halogenated furanones. These inhibitors act by interfering with the corresponding signal binding to the receptor (Lyon et al. 2000) or decreasing the receptor concentration (Manefield et al. 2002; Lade et al. 2014). The other group is the enzyme inhibitors, such as triclosan and closantel that inhibit enoyl-ACP reductase, whose products are the essential intermediate in AHL biosynthesis (Czajkowski and Jafra 2009).

Both bacterial pathogens and symbionts require QS to colonise and invade their hosts (Loh et al. 2002). In view of the bacterial dependence on QS for the infection of hosts, it makes good evolutionary sense that eukaryotes have acquired the ability to recognise and respond to bacterial QS signals (Smith and Iglewski 2003) and the ability to actively interfere with bacterial QS through the production of compounds that mimic or inhibit the bacterial signals (Bauer and Teplitski 2001). Plants have been shown to produce secondary metabolites (Zare et al. 2012; Mohamed 2014) and plants also produce AHL mimic compounds, possibly to manipulate the microbial rhizosphere population (Tolmacheva et al. 2014). Seedlings of various plant species and exudates from pea (Pisum sativum L.) seedling induce swarming in Serratia liquefaciens (Grimes and Hennerty 1931) and activate several AHL reporter systems, in addition to inhibiting QS-regulated phenotypes in Chromobacterium violaceum (Schröter 1872) (Teplitski et al. 2000). Various higher plants including pea seedlings, garlic (Allium sativum L.), alfalfa (Medicago sativa L.), vanilla (Vanilla sp. Mill.), sausage tree (Kigelia africana Benth.), chamomile (Matricaria sp.), water lily (Nymphaea sp.), various peppers (Capsicum spp.), black salsify (Scorzonera sandrasica L.) and jelly fungus (Tremella fuciformis L.) were 
also shown to secrete AHL signal mimicing substances and were also found to have anti-QS activity (Teplitski et al. 2000; Gao et al. 2003; Chenia 2013).

Because of the lack of effective and safe plant protection products, the control of bacterial diseases is much more difficult than the control of fungal diseases (Mansoori et al. 2013; Samavat et al. 2014). Using QS as a target to control and handle detrimental infections caused by human, animal, and plant pathogens, is potentially an attractive strategy. Although QS systems are used by many bacterial pathogens to regulate virulence, they are not essential for survival. Thus, disruption of QS (so-called "quorum quenching") should attenuate pathogenicity without imposing the level of selective pressure associated with antibacterial treatments (Cirou et al. 2009; Mahmoudi et al. 2013a; Yap et al. 2014). This study aimed to test the QS interfering activity of lettuce against bacterial QS, in order to detect effective compounds which assayed to induce QS regulation behaviors in bioreporter strain and plant pathogenic bacterium.

\section{Materials and Methods}

\section{Plant material and extraction}

Seeds of lettuce (Lactuca sativa L.) were surface disinfected using sodium hypochlorite solution (5\%) for $1 \mathrm{~min}$. The seeds were then washed twice with sterilised water and put in a sterilised peat substrate, to grow under greenhouse conditions $\left(28^{\circ} \mathrm{C}\right.$, with $50-70 \%$ humidity and 30,000 lux light) with a $16: 8 \mathrm{~h}$ light-dark photoperiod. Plants were taken for extraction after 5 weeks, the roots were cut and the aerial parts of the plants were washed several times using sterile water. Five grams of fresh aerial plant material were frozen with liquid nitrogen and ground using a mortar. The fine powder obtained was suspended in ethyl acetate after acidifying with $0.1 \%$ glacial acetic acid, and mixed for $5 \mathrm{~min}$. The plant residues were removed using paper filter (Whatman paper no. 1) and the extracts stored at $-20^{\circ} \mathrm{C}$ for $1 \mathrm{~h}$. Samples of extracts to be analysed were dried under a stream of sterile air and the residue redissolved in proper solvents.

\section{Violacein induction in C. violaceum CV026 by plant extracts}

In a disc-diffusion assay, $50 \mu \mathrm{l}$ of $C$. violaceum $\mathrm{CV} 026$ with $1.8 \times 10^{6} \mathrm{cfu} \cdot \mathrm{ml}^{-1}$ was streaked on Luria Bertani Agar (LBA) medium. Four sterilised discs (6 mm diameter) containing $20 \mu \mathrm{l}$ of concentrated lettuce extract were placed on each plate. The plates were then incubated overnight at $30^{\circ} \mathrm{C}$ and QS induction was detected as a purple colouration of the colony of the bioreporter strain. To ensure the sterility of the extracts and to minimise any introduction of exogenous QS induction compounds, extracts were sterilised using $0.45 \mu \mathrm{m}$ membrane and extracts were tested for microbial contamination before the violacein induction assay by streaking onto LBA plates. Incubation was done at $27^{\circ} \mathrm{C}$ overnight. In a second method, surface disinfected aerial parts of plants were crushed with a sterilised mortar. One gram of plant residue was placed on LBA that had been previously inoculated with $50 \mu \mathrm{l}$ of a $1.8 \times 10^{6} \mathrm{cfu} \cdot \mathrm{ml}^{-1}$ suspension of CV026 strain. The plates were then incubated at $30^{\circ} \mathrm{C}$ for $48 \mathrm{~h}$. In the both methods, $5 \mathrm{mg} \cdot \mathrm{l}^{-1}$ of standard C6-HSL (purchased from Sigma-Aldrich, Inc., St. Louis, Mo., USA) was used as the positive control for exogenous QS signal.

\section{Determination of chemical compounds in L. sativa}

Thin Layer Chromatography (TLC): Crude extract in the ethyl acetate of $L$. sativa (see above) was separated by thin layer chromatography on a $\mathrm{C}_{18}$-reversed phase plate (Sigma Aldrich, Inc., St. Louis, Mo., USA). Concentrated extract $(20 \mu \mathrm{l})$ was spotted on the plate and $5 \mu \mathrm{l}$ of C6-HSL $\left(5 \mathrm{mg} \cdot \mathrm{l}^{-1}\right)$ was used as the positive control. The plate was developed with a solvent system of methanolwater $(60: 40, \mathrm{v} / \mathrm{v})$ according to Shaw et al. (1997). After development, the solvent was evaporated, and the dried plates were overlaid with a culture of CV026, as described by McClean et al. (1997).

Gas chromatography/mass spectrometry (GC-MS) analysis was performed using an Agilent 5975 gas chromatograph equipped with a HP-5MS column (30 m $\times$ $\times 0.25 \mathrm{~mm}$, film thickness $0.25 \mu \mathrm{m})$. Oven temperature was maintained at $50^{\circ} \mathrm{C}$ for $5 \mathrm{~min}$ and then programmed to $265^{\circ} \mathrm{C}$ at a rate of $2.5^{\circ} \mathrm{C} \cdot \mathrm{min}^{-1}$. The injector and detector (FID) temperature was $250^{\circ} \mathrm{C}$ and helium was used as the carrier gas. Percentages were calculated by electronic integration of FID peak areas without the use of response factor correction. The MS was run in the electron ionisation mode, using ionisation energy of $70 \mathrm{eV}$.

\section{Soft rot induction in tuber maceration assay}

Potato tubers of Solanum tuberosum cv. Agria were surface sterilised with $10 \%$ sodium hypochlorite for $2 \mathrm{~min}$, rinsed with tap water, and air-dried. In the middle of each tuber, one puncture wound ( $6 \mathrm{~mm}$ in diameter and $3 \mathrm{~mm}$ deep) was made. An overnight culture $\left(27^{\circ} \mathrm{C}\right.$ with $200 \mathrm{rpm}$ shaking) of the Pectobacterium carotovorum subsp. carotovorum strain EMPCC $(P c c)$ in LBA medium was collected by centrifugation $(2,000 \mathrm{~g}$ for $10 \mathrm{~min}$ at room temperature) and washed twice using $0.8 \% \mathrm{NaCl}$. The bacterial pellet was resuspended in $0.8 \% \mathrm{NaCl}$ and each tuber $(\mathrm{n}=4$ per conditions) was inoculated with $20 \mu \mathrm{l}$ of Pcc suspensions at two concentrations $\left(2.5 \times 10^{6}\right.$ and $\left.2.5 \times 10^{3} \mathrm{cfu} \cdot \mathrm{ml}^{-1}\right)$ in the presence of $20 \mu \mathrm{l}$ of the lettuce extract. The inoculated tubers were incubated at $27^{\circ} \mathrm{C}$ in a moist chamber $(80 \%$ humidity). Four days after inoculation, the tubers were cut transversely, photographed, and the disease severity was estimated according to the percentage of tissue maceration.

\section{Results}

In this research, aerial parts of L. sativa were tested for QS interfering activity as described above. Adding $20 \mu \mathrm{l}$ of lettuce extract to paper discs on the media, led to the production of a violet pigment in colonies of $C$. violaceum CV026. The amount of pigment production was generally very low, but these few purplish colonies showed that the extract could stimulate the QS system in CV026 bacteri- 
um. These results were further confirmed when crushed plant material was directly put on the media and a high pigment production was observed in CV026 colonies (Fig. 1A). In this method, all plant tissues and their exudates were directly presented to the indicator bacterium. Apparently, there was a high concentration of AHL similar molecules in the bacterium environment which caused the increase in pigment production. Inhibition of bacterial growth around the crushed plants, was not observed.

The induction of violacein synthesis in areas adjacent to the plant material was similar to that caused by the addition of C6-HSL to a lawn on CV026 medium.

The thin layer chromatogram showed that bioreporter strain, CV026, was only detected on one spot on lettuce extract. The lettuce extract produced a pale, tailing, diffuse edge as the control treatment were used $5 \mu \mathrm{l}$ of C6-HSL solution $\left(5 \mathrm{mg} \cdot \mathrm{l}^{-1}\right)$. The five $\mu \mathrm{l}$ of $\mathrm{C} 6$-HSL solution caused a large spot on the TLC plate (Fig. 1B).

The lettuce extract's GC-MS and GC-FID analysis revealed that the lettuce extract consisted of 19 compounds, of which homoserine accounted for $2.37 \%$ of the total constituents (Fig. 2). The ability of L. sativa extract (containing herbal homoserine) to suppress the QS system was assessed. As was expected, no QS inhibition activity was observed in the L. sativa extract in the presence of C6-HSL. Finally, the ability of the QS stimulating extract on pathogenicity of $P$. carotovorum was studied at different concentrations of bacterium. Adding $20 \mu \mathrm{l}$ of lettuce extract to the bacterial suspension (with concentrations of $10^{3} \mathrm{cfu} \cdot \mathrm{ml}^{-1}$ ) caused more severe soft rot symptoms in potato tubers than tubers inoculated with only $10^{3} \mathrm{cfu} \cdot \mathrm{ml}^{-1}$ of pathogenic bacterium (Fig. 3). On the other hand, injecting a low concentration $\left(10^{3}\right.$ times less) of PcC simultaneously with the plant extract showed the same disease level as tubers inoculated with a concentration of $10^{6} \mathrm{cfu}$. - $\mathrm{ml}^{-1}$ of Pcc alone. As shown in figure 3, adding extract containing AHL mimic compounds to the bacterial suspension brought about an increase in disease caused by Pcc. In other words, P. carotovorum might be able to also identify AHL mimic molecules of plants, and use them as signal molecules. An increase in the concentration of bacterial AHL molecules (because of bacterial multiplication), and AHL similar molecules (from adding the plant extract) in the bacterial environment caused an overexpression of cell wall degradation enzymes and these caused an increase in soft rot symptoms in potato tuber. This was true despite the fact that the population of bacteria (cell density) was $10^{3}$ times less than that used in the control $\left(10^{6} \mathrm{cfu} \cdot \mathrm{ml}^{-1}\right)$.

\section{Discussion}

In plant pathology, there is much interest in finding natural or synthetic compounds active in small quantities, that are capable of interfering with QS in pathogenic bacteria in order to disrupt the bacteria's pathogenicity/virulence production factor. In attempting to learn whether $L$. sativa secretes substances that mimic AHL signal molecules in regulating population density-dependent behaviors, we relied on the bacterium reporter strain, $C$. violaceum strain CV026. This strain was carefully mutated by oth- ers to detect exogenous AHLs (McClean et al. 1997). The addition of one gram of lettuce residue to the LBA medium produced pigment in C. violaceum CV026 colonies. There was no QS inhibition activity of L. sativa observed in the presence of C6-HSL in biosensor colonies. Only stimulation of the signal behaviour in the QS system of bioreporter strain took place. The detection of the presence of homoserine in lettuce extract is an important fact because homoserine is a part of the bacterial signal molecules, known as AHL. Acyl homoserine lactones are the main QS signal molecules of Gram-negative bacteria. All AHL are composed of the homoserine lactone ring and the acyl side chain, their signaling activities are related to the lactone ring. These molecules are very sensitive to elevated temperatures and also to alkaline $\mathrm{pH}$. With an increase in the $\mathrm{pH}$ or the temperature, AHL rapidly degrade. The mechanism involved in these degradations is lactonolysis, which leads to the generation of acyl-homoserine that does not function as a QS signal molecule (Yates et al. 2000). The bioassay results of this research revealed that lettuce extract induced QS in the bioreporter strain, CV026. Ours is the first report showing that lettuce contains AHL-like substances (homoserine) which excite AHL related QS in bacteria. This homoserine might be a part or a residue of plant AHL lactone that degraded during in the extraction process. Up till now, the chemical structure of the AHL mimic-compounds have not been well identified, and most of these compounds have QS inhibitory activity that interferes with QS related behavior in studied bacteria (Chang et al. 2014; Yap et al. 2014).

It is known that plant extracts have, indeed, a QS interfering activity in C. violaceum. The possibility that these plant extracts may also be able to affect QS-mediated phenotypes in other Gram-negative bacteria, was investigated. The Pectobacterium carotovorum subsp. carotovorum was chosen for this purpose because of its known QS systems that control a number of genes involved in biofilm formation and production of virulence factors such as pectinolytic enzymes (Barnard and Salmond 2007; Essarts et al. 2013; Mahmoudi et al. 2013a). Quorum sensing mutants of $P$. carotovorum have been shown to have a lower production of pectinolytic enzymes than wildtype strains (Mahmoudi et al. 2013a). We found that the presence of the lettuce extract in bacterial suspension significantly increased the symptoms of soft rot disease as compared to the inoculation of $P C C$ alone. These results indicate that plant extracts may act as signals for the regulation of bacterial virulence. Our findings support previous work which suggested that fenugreek (Trigonella foenum-graecum L.), white clover (Trifolium repens L.) (Mahmoudi et al. 2013b) and rice plants (Oryza sativa L.) (Degrassi et al. 2007) contain molecules which stimulated QS related functions in bioreporter strains. The existence of imitator compounds of bacteria signal molecules, either in an exciting and induction form or in a destruction and suppression form, can be an appropriate platform for improving chemical control methods based on environment protection and using effective compounds of plants (Keshavan et al. 2005; Rasmussen and Givskov 2006). The chemical nature of the active AHL mimics compounds from plants and active AHL effect on bacterial QS could 

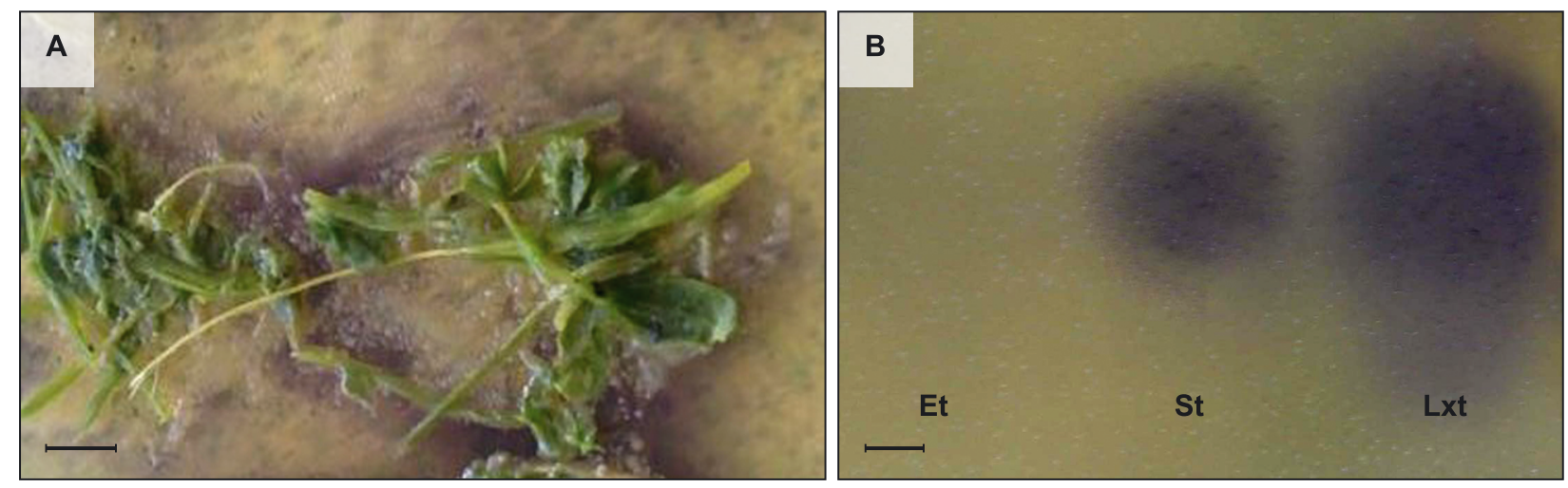

Fig. 1. Induction of quorum sensing (QS) in Chromobacterium violaceum CV026 by crushed lettuce (Lactuca sativa) material (A). Purification and detection of the acyl homoserine lactone (AHL)-like component from vegetative phase of lettuce extract (B). Lettuce extract $(15 \mu \mathrm{l})$ purified by ethyl acetate, and $5 \mu \mathrm{l}$ of $\mathrm{C} 6$-HSL $\left(5 \mathrm{mg} \cdot \mathrm{l}^{-1}\right)$, as the positive control, were separated on a $\mathrm{C}_{18}$ silica plate with a solvent system of methanol-water $(60: 40, \mathrm{v} / \mathrm{v})$. The violet spots represent the presence of molecules that are able to induce the AHL related QS in biosensor C. violaceum CV026 strain. Et - $15 \mu \mathrm{l}$ of ethyl acetate as the negative control; St - $5 \mu \mathrm{l}$ of C6-HSL standard; Lxt - lettuce extract. The lettuce extract produced a big tailing spot with a diffuse edge. Bars: A - $5 \mathrm{~mm}, \mathrm{~B}-7 \mathrm{~mm}$

A<smiles>CCCCCC(=O)NC1CCOC1=O</smiles>

B<smiles>NC(CCO)C(=O)O</smiles>

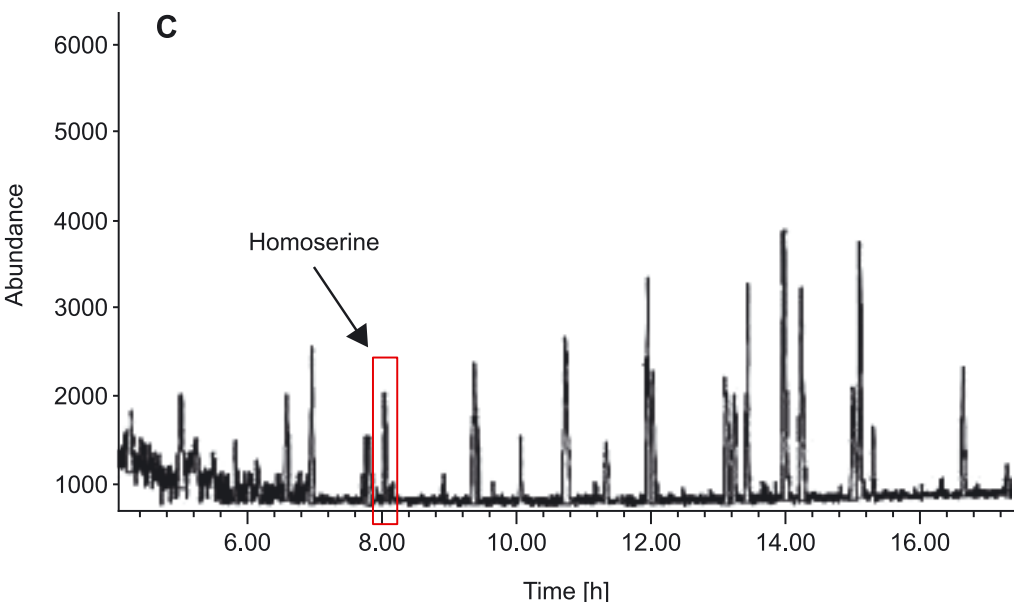

Fig. 2. Structures of N-hexanoyl homoserine lactone (A) and homoserine molecules in Lactuca sativa extract (B). GC-MS analysis (total ion chromatogram) of the lettuce extract using $\mathrm{DB}_{5}$ fused silica column, $30 \mathrm{~m} \times 0.25 \mathrm{~mm} \times 0.25 \mu \mathrm{m}(\mathrm{C})$

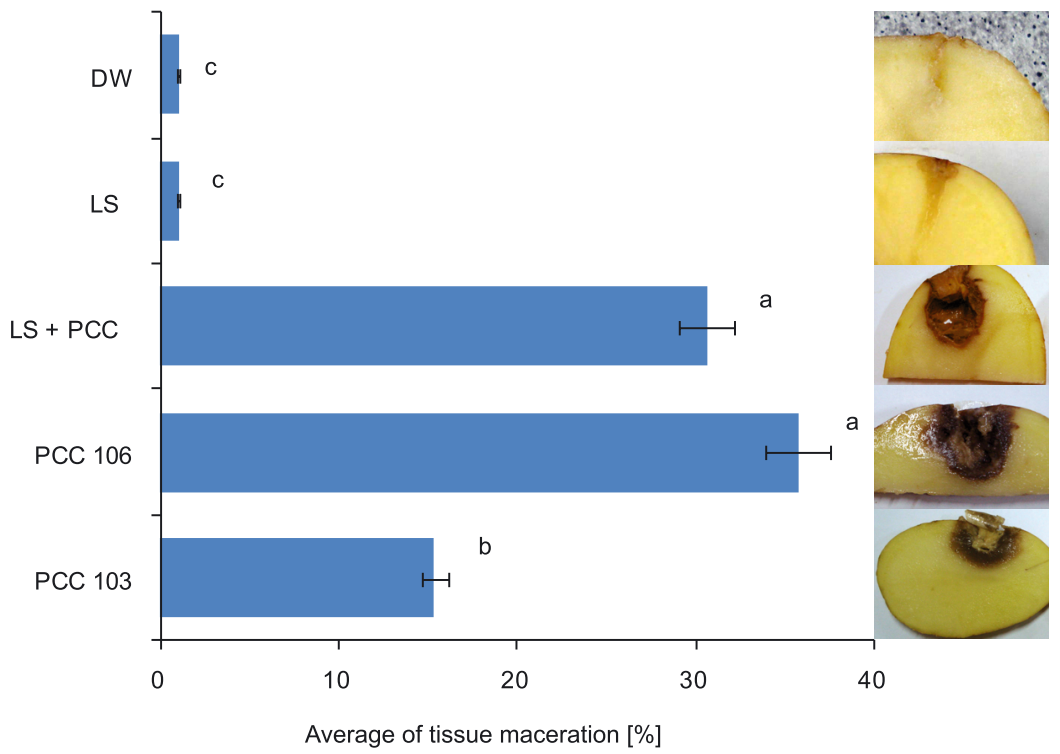

Fig 3. The effect of the acyl homoserine lactone (AHL) mimicking-compounds from Lactuca sativa (LS) on the virulence of Pectobacterium carotovorum (PCC) on potato tubers. Significant increasing of potato soft rot in co-inoculation of potato tubers with PCC and lettuce extract. Development of tissue maceration and soft rot disease on potato were increased after low concentrations $\left(10^{3} \mathrm{cfu} \cdot \mathrm{ml}^{-1}\right)$ of lettuce extract was added to bacterial suspension. Data are presented as the mean \pm SD. PCC $103-20 \mu \mathrm{l}$ of bacterial suspension at $10^{3} \mathrm{cfu}$; PCC $106-20 \mu \mathrm{l}$ of bacterial suspension at $10^{6} \mathrm{cfu}$; LS + PCC $-20 \mu \mathrm{l}$ of bacterial suspension at $10^{3} \mathrm{cfu}$ and with $20 \mu \mathrm{l}$ of lettuce extract; LS $-20 \mu \mathrm{l}$ of lettuce extract; DW $-20 \mu \mathrm{l}$ of distilled water as the control 
be one of the intrinsic plants defense mechanism against pathogenic invasions. Using herbal compounds with QS system induction properties can increase pathogenicity of plant pathogenic bacteria (as shown in this study). However, these compounds can increase the production of antibiotic or QS dependent secondary metabolites in useful bacteria. Biological control agents can use herbal compounds to increase antagonistic ability.

\section{Acknowledgements}

The author is thankful for the research grant provided by the Research Council of the Isfahan (Khorasgan) Branch, Islamic Azad University, Iran.

\section{References}

Amara N., Krom B.P., Kaufmann G.F., Meijler M.M. 2011. Macromolecular inhibition of quorum sensing: enzymes, antibodies, and beyond. Chemical Reviews 111 (1): 195-208.

Barnard A.M., Salmond G.P. 2007. Quorum sensing in Erwinia species. Analytical and Bioanalytical Chemistry 387 (2): 415-423.

Bauer W.D., Teplitski M. 2001. Can plants manipulate bacterial quorum sensing? Australian Journal of Plant Physiology 28: 913-921.

Chang C.Y., Krishnan T., Wang H., Chen Y., Yin W.F., Chong Y.M., Tan L.Y., Chong T.M., Chan K.G. 2014. Non-antibiotic quorum sensing inhibitors acting against $\mathrm{N}$-acyl homoserine lactone synthase as druggable target. Scientific Reports 4: 7245 . DOI: $10.1038 /$ srep07245.

Chenia H.Y. 2013. Anti quorum sensing potential of crude Kigelia africana fruit extract. Sensore 13 (3): 2802-2817.

Cirou A., Uroz S., Chapelle E., Latour X., Orange N., Faure D., Dessaux Y. 2009. Quorum sensing as a target for novel biocontrol strategies directed at Pectobacterium. p. 121-31. In: "Recent Developments in Management of Plant Diseases Gisi" (U.I. Chet, M.L. Gullino, eds.). Dordrecht, Springer, $377 \mathrm{pp}$.

Cotar A.I. 2013. Quorum sensing inhibitors as anti-pathogenic drugs in the fight against Pseudomonas aeruginosa infections. Clinical Microbiology 2: e111. DOI: 10.4172/2327$5073.1000 \mathrm{e} 111$.

Czajkowski R., Jafra S. 2009. Quenching of acyl-homoserine lactone-dependent quorum sensing by enzymatic disruption of signal molecules. Acta Biochimica Polonica 56 (1): 1-16.

Degrassi G., Devescovi G., Solis R., Steindler L., Venturi V. 2007. Oryza sativa rice plants contain molecules that activate different quorum-sensing $\mathrm{N}$-acyl homoserine lactone biosensors and are sensitive to the specific AiiA lactonase. FEMS Microbiology Letters 269: 213-220.

Essarts Y.R., Sabbah M., Comte A., Soulere L., Queneau Y., Dessaux Y., Helias V., Faure D. 2013. N,N'-Alkylated imidazolium-derivatives act as quorum-sensing inhibitors targeting the Pectobacterium atrosepticum-induced symptoms on potato tubers. International Journal of Molecular Sciences 14 (10): 19976-19986.

Gao M., Teplitski M., Robinson J.B., Bauer W.D. 2003. Production of substances by Medicago truncatula that affect bacterial quorum sensing. Molecular Plant Microbe Interaction 16 (24): 827-834.
Keshavan N.D., Chowdhary P.K., Haines D.C., González J.E. 2005. L-canavanine made by Medicao sativa interferes with quorum sensing in Sinorhizobium meliloti. Journal of Bacteriology 187: 8427-8436.

Lade H., Paul D., Kweon J.H. 2014. Quorum quenching mediated approaches for control of membrane biofouling. International Journal of Biological Sciences 10 (5): 550-565.

Loh J., Pierson E.A., Pierson L.S., Stacey G., Chatterjee A. 2002. Quorum sensing in plant-associated bacteria. Current Opinion in Plant Biology 5 (4): 285-290.

Lyon G.J., Mayville P., Muir T.W., Novick R. 2000. Rational design of a global inhibitor of the virulence response in Staphylococcus aureus, based in part on localization of the site of inhibition to the receptor-histidine kinase, AgrC. Proceedings of the National Academy of Sciences USA 97: 13330-13335.

Mahmoudi E., Naderi D., Venturi V. 2013a. AiiA lactonase disrupts $\mathrm{N}$-acylhomoserine lactone and attenuates quorum sensing related virulence in Pectobacterium carotovorum EMPCC. Annals of Microbiology 63 (2): 691-697.

Mahmoudi E., Tarzaban S., Khodaygan P., Abed A. 2013b. Acyl homoserin lactone mimic compounds from plants excite quorum sensing related behaviors in Chromobacterium violaceum CV026 and Pectobacterium carotovorum. International Journal of Forest, Soil and Erosion 3 (4): 141-145.

Manefield M., Rasmussen T.B., Henzter M., Andersen J.B., Steinberg P., Kjelleberg S., Givskov M. 2002. Halogenated furanones inhibit quorum sensing through accelerated LuxR turnover. Microbiology 148 (4): 1119-1127.

Mansoori M., Heydari A., Hassanzadeh N., Rezaee S., Naraghi L. 2013. Evaluation of Pseudomonas and Bacillus bacterial antagonists for biological control of cotton Verticillium wilt disease. Journal of Plant Protection Research 53 (2): 154-157.

McClean K.H., Winson M.K., Fish L., Taylor A., Chhabra S.R., Camara M., Dayykin M., Lamb J.H., Swift S., Bycroft B.W. 1997. Quorum sensing and Chromobacterium violaceum: exploitation of violacein production and inhibition for the detection of $\mathrm{N}$-acyl homoserine lactones. Microbiology 143 (12): 3703-3711.

Mohamed B.Z.A. 2014. Plant extract control of the fungi associated with different Egyptian wheat cultivars grains. Journal of Plant Protection Research 54 (3): 232-237.

Rasmussen T.B., Givskov M. 2006. Quorum sensing inhibitors: a bargain of effects. Microbiology 152 (4): 895-904.

Samavat S., Heydari A., Zamanizadeh H.R., Rezaee S., Aliabadi A.A. 2014. A comparison between Pseudomonas aureofaciens (chlororaphis) and P. fluorescens in biological control of cotton seedling damping-off disease. Journal of Plant Protection Research 54 (2): 115-121.

Shaw P.D., Ping G., Daly S.L., Cha C., Cronan J.E., Rinehart K.L., Farrand S.K. 1997. Detecting and characterizing N-acyl-homoserine lactone signal molecules by thin layer chromatography. Biochemical Journal 94 (12): 6036-6041.

Smith R.S., Iglewski B.H. 2003. Pseudomonas aeruginosa quorum-sensing systems and virulence. Current Opinion in Microbiology 6 (1): 56-60.

Teplitski M., Robinson J.B., Bauer W.D. 2000. Plants secrete substances that mimic bacterial $\mathrm{N}$-acyl homoserine lactone signal activities and affect population density-dependent 
behaviors in associated bacteria. Molecular Plant-Microbe Interaction 13 (6): 637-648.

Tolmacheva A.A., Rogozhin E.A., Deryabini D.G. 2014. Antibacterial and quorum sensing regulatory activities of some traditional Eastern-European medicinal plants. Acta Pharmaceutica 64 (2): 173-186.

Yap P.S.X., Krishnan T., Yiap B.C., Hu C.P., Chan K.G., Lim S.H.E. 2014. Membrane disruption and anti-quorum sensing effects of synergistic interaction between Lavandula angustifolia (lavender oil) in combination with antibiotic against plasmid-conferred multi-drug-resistant Escherichia coli. Journal of Applied Microbiology 116 (5): 1119-1128.
Yates E.A., Philipp B., Buckley C., Atkinson S., Chhabra S.R., Sockett R.E., Goldner M., Dessaux Y., Camara M.M., Smith H. 2002. N-Acylhomoserine lactones undergo lactonolysis in a $\mathrm{pH}-$, temperature-, and acyl chain length-dependent manner during growth of Yersinia pseudotuberculosis and Pseudomonas aeruginosa. Infection and Immunity 70 (10): 5635-5646.

Zare Z., Majd A., Sattari T.N., Iranbakhsh A., Mehrabian S. 2012. Antimicrobial activity of leaf and flower extracts of Lippia nodiflora L. (Verbenacea). Journal of Plant Protection Research 52 (4): 401-403. 